\title{
Prevalence and Antibiotic Resistance of Salmonella spp. in Turkey
}

\author{
Mohammad Jahantigh ${ }^{1 *}$, Seyede Maryam Jafari², Ahmad Rashki ${ }^{3}$, Saeed Salari ${ }^{3}$ \\ ${ }^{1}$ Department of Poultry Diseases, School of Veterinary Medicine, University of Zabol, Zabol, Iran \\ ${ }^{2}$ School of Veterinary Medicine, University of Zabol, Zabol, Iran \\ ${ }^{3}$ Department of Pathobiology, School of Veterinary Medicine, University of Zabol, Zabol, Iran \\ Email: *mjahantig@yahoo.com
}

Received 18 July 2015; accepted 28 August 2015; published 31 August 2015

Copyright (C) 2015 by authors and Scientific Research Publishing Inc.

This work is licensed under the Creative Commons Attribution International License (CC BY). http://creativecommons.org/licenses/by/4.0/

c) (i) Open Access

\begin{abstract}
The current study was conducted to investigate the prevalence of Salmonella spp. in turkey and to determine the antimicrobial resistance pattern of the isolated Salmonellae. Two hundred and fifty turkeys were randomly selected for cloacal soab samples preparation, and the samples were investigated for Salmonella isolation. Identification of the isolated Salmonella was performed using standard bacteriological and biochemical procedures. The prevalence of Salmonella in turkey was about $14.8 \%$. Disc diffusion tests on Muller-Hinton agar were used to determine the sensitivity to antibacterial agents. Ten antibiotics were studied: lincospectin, colistin, cephalexin, ciprofloxacin, chloramphenicol, gentamycin, furazolidone, streptomycin, co-trimoxazole (trimethoprim-sulfamethoxazole) and tetracycline. The highest resistant was observed against cephalexin $(89.2 \%)$, tetracycline (86.5\%), colistin $(83.8 \%)$, and furazolidone (73\%). The Highest sensitivity was found to gentamycin (86.5\%), ciprofloxacin $(83.8 \%)$, chloramphenicol $(51.4 \%)$ and streptomycin $(40.6 \%)$. The results showed high prevalence of Salmonella spp. in turkey and high levels of antimicrobial resistance pattern of the isolated Salmonellae were observed.
\end{abstract}

\section{Keywords}

Antibiotic Resistance, Prevalence, Salmonella, Turkey

\section{Introduction}

Salmonellosis is one of the common diseases in all places. Unhygienic farm condition is major predisposing factor for cause of this disease. Some of the diseases of Salmonella are transmissible from man to birds. In the

${ }^{*}$ Corresponding author. 
Salmonellosis, transmission of diseases to human beings is an important criteria rather than drop in production in the farm [1]. Infections with bacteria of the genus Salmonella are responsible for a variety of acute and chronic diseases in poultry. Infected poultry flocks are also among the most important reservoirs of Salmonellae that can be transmitted through the food chain to humans [2]. Salmonella is a genus of bacterium that is a major cause of foodborne illness throughout the world. The main reservoirs of Salmonella are considered to be domestic animals, poultry and pigs in particular and Salmonella organisms are easily isolated from faeces [3]. These carrier animals likely play a significant role in the spread of infection between herds and flocks and consequently serve as sources of food contamination and human infection [4]. Salmonella spp. is routinely detected in clinical, food and environmental samples using microbiological culture after an enrichment step [5]. Resistance to antibacterial drugs is an increasingly important problem in both humans and animals. The widespread, sometimes indiscriminate, use of these drugs results in the selection of bacteria which are inherently resistant. Not only may these resistant bacteria become the predominant species in a population but they may also transfer genetic material to susceptible bacteria which then acquire resistance [6]. The spread of antibiotic resistances through the food chain remains a relevant question for both researchers and public health operators.

In Iran there are no reports regarding the prevalence of Salmonellae in turkey flocks and its antibacterial resistance. The objectives of the present study were to investigate the prevalence of Salmonella spp. in turkey flocks and to characterize the antimicrobial resistance of the isolated Salmonella.

\section{Methodology}

\subsection{Sample Collection}

Cloacal soab samples were prepared from 250 randomly selected turkeys and the soabs were transferred to the laboratory of microbiology of Zabol University and were investigated for the presence of Salmonella.

\subsection{Culture and Isolation}

For Salmonella isolation, the primary enrichment of samples in Selenite- $\mathrm{F}$ at $37^{\circ} \mathrm{C}$ for 24 hours was followed by subculture on Salmonella-Shigella agar and the plates were incubated at $37^{\circ} \mathrm{C}$ for 24 hours. The plates were observed for colony formation after 24 - 48 hours of incubation. Pure cultures were prepared from Salmonella like colonies and were used for identification of the organisms by bacteriological methods as described previously by Quinn et al. (2002) and Swayne et al. (1998) [7] [8].

\subsection{Antimicrobial Susceptibility Testing}

For determination of susceptibility to antibacterial agents, the disc diffusion method on Muller-Hinton agar was used. The following antimicrobial agents were tested: co-trimoxazole (trimethoprim-sulfamethoxazole) (1.25/ $23.75 \mu \mathrm{g})$, colistin $(10 \mu \mathrm{g})$, cephalexin $(30 \mu \mathrm{g})$, ciprofloxacin $(5 \mu \mathrm{g})$, chloramphenicol $(30 \mu \mathrm{g})$, gentamycin $(10$ $\mu \mathrm{g})$, furazolidone $(100 \mu \mathrm{g})$, streptomycin $(10 \mu \mathrm{g})$, lincospectin $(15 / 200 \mu \mathrm{g})$ and tetracycline $(30 \mu \mathrm{g})$. All antibacterial disks were provided from Padtan Teb Company (Tehran, Iran). Following the application of antimicrobial discs, the plates were incubated at $37^{\circ} \mathrm{C}$ for 24 hours. The diameters of the zones of inhibition were measured (millimetres) and were compared to internationally accepted measurements to determine the susceptibility or resistance of the isolate [9]. Drug resistance patterns of the organisms were determined at three levels: Susceptible (S), Intermediate (I) and Resistant (R). The numbers of isolates of Salmonella which showed S, I and R patterns were determined. The percentages of antimicrobial resistance of each pattern (S, I and R) of isolates were calculated and reported as the results.

\section{Results}

Bacteriological studies showed the prevalence of Salmonella in turkey flocks about $14.8 \%$. The results showed high levels of antimicrobial resistance pattern of the isolated Salmonellae. The highest resistance to cephalexin (89.2\%) and followed resistance to tetracycline (86.5\%), colistin (83.8\%), furazolidone (73\%), co-trimoxazole (67.6\%), lincospectin (59.6\%), streptomycin (43.2\%), chloramphenicol (40.5\%), gentamycin (5.4\%) and ciprofloxacin (2.7\%) were observed. The rates of susceptibility were against gentamycin (86.5\%), ciprofloxacin (83.8\%), chloramphenicol (51.4\%), streptomycin (40.6\%), lincospectin (29.7\%), furazolidone and co-trimoxa- 
zole (13.5\%), cephalexin (10.8\%), tetracycline (5.4\%) and colistin (0\%). Antibacterial resistances pattern of isolated Salmonellae are shown in Table 1 and Table 2.

\section{Discussion}

In the present study, $14.8 \%$ of turkeys were Salmonella positive, but another study in Iran reported that prevalence of Salmonella in sample of turkeys' liver and heart was 8.6\% and in turkeys' meat was 6.7\% [10] [11]. In one study conducted in Austria, only one Salmonella isolate was recovered from 262 turkey meat samples [12]. Since Salmonellosis is transmitted primarily through food, particularly food of animal origin, therefore, we recommend more restrictions on the irrational use of antibiotics and public awareness activities should be undertaken to alert the public to the risks of the unnecessary use of antibiotics [10].

Among antibiotics used in this study, the highest resistant was observed against cephalexin (89.2\%), tetracycline (86.5\%), colistin (83.8\%), and furazolidone (73\%). High prevalence of resistance could be related to uncontrolled use of these antimicrobial agents in the treatment of bacterial infection. Besides, the highest sensitivity was found to gentamycin (86.5\%), ciprofloxacin (83.8\%), chloramphenicol (51.4\%) and streptomycin (40.6\%). The high sensitivity of the isolated Salmonella to the mentioned antibiotics could be related to less frequent usage of these drugs for therapeutic purposes, therefore reducing the chance for resistance to develop.

Jahantigh and Nili (2010) investigated drug resistance to Salmonella spp. isolated from pigeon eggs in Iran. Resistance to antibacterial drugs were tetracycline (50\%), ampicillin, cephalexin and furazolidone (25\%). No resistance was observed against colistin, ciprofloxacin, chloramphenicol, gentamycin, nalidixic acid and norfloxacin [13]. Antibiotic resistance pattern of S. typhimurium isolated from dead-in-shell chicken embryo in Iran was $10 \%$ for tetracycine, chloramphenicol, furazolidone and cephalexin [14]. Drug resistance of Salmonella spp. from human and different animal sources has been a matter of concern and investigated by numerous authors [15]-[19].

\section{Conclusion}

As animals are a main reservoir of Salmonella and the use of antimicrobials in food animals for therapy, prophylaxis and growth promotion accelerate the emergence of antimicrobial resistant pathogens, it is not surprising that an increased number of human Salmonellosis cases are caused by foodborne antimicrobial resistant Salmonella

Table 1. The numbers of antibacterial resistance patterns of Salmonella spp. isolated from turkey.

\begin{tabular}{|c|c|c|c|c|c|c|c|c|c|c|}
\hline \multicolumn{11}{|c|}{ Antibacterial agent } \\
\hline Results & $\mathrm{S} 10$ & CL30 & CL10 & $\mathrm{CP}$ & $\mathrm{C}$ & GM & FR & SXT & LP & $\mathrm{TE}$ \\
\hline S (n) & 15 & 4 & 0 & 31 & 19 & 32 & 5 & 5 & 11 & 2 \\
\hline I (n) & 6 & 0 & 6 & 5 & 3 & 3 & 5 & 7 & 4 & 3 \\
\hline $\mathrm{R}(\mathrm{n})$ & 16 & 33 & 31 & 1 & 15 & 2 & 27 & 25 & 22 & 32 \\
\hline Total (n) & 37 & 37 & 37 & 37 & 37 & 37 & 37 & 37 & 37 & 37 \\
\hline
\end{tabular}

S10: streptomycin, CL30: cephalexin, CL10: colistin, CP: ciprofloxacin, C: chloramphenicol, GM: gentamycin, FR: furazolidone, SXT: co-trimoxazole, LP: lincospectin, TE: tetracycline, S: Susceptible, I: Intermediate, R: Resistant.

Table 2. The percent of antibacterial resistance patterns of Salmonella spp. isolated from turkey.

\begin{tabular}{|c|c|c|c|c|c|c|c|c|c|c|}
\hline \multicolumn{11}{|c|}{ Antibacterial agent } \\
\hline Results & $\mathrm{S} 10$ & CL30 & CL10 & $\mathrm{CP}$ & $\mathrm{C}$ & GM & FR & $\mathrm{SXT}$ & LP & $\mathrm{TE}$ \\
\hline $\mathrm{S}(\%)$ & 40.6 & 10.8 & 0 & 83.8 & 51.4 & 86.5 & 13.5 & 13.5 & 29.7 & 5.4 \\
\hline I (\%) & 16.2 & 0 & 16.2 & 13.5 & 8.1 & 8.1 & 13.5 & 18.9 & 10.8 & 8.1 \\
\hline R (\%) & 43.2 & 89.2 & 83.8 & 2.7 & 40.5 & 5.4 & 73 & 67.6 & 59.5 & 86.5 \\
\hline Total (\%) & 100 & 100 & 100 & 100 & 100 & 100 & 100 & 100 & 100 & 100 \\
\hline
\end{tabular}

S10: streptomycin, CL30: cephalexin, CL10: colistin, CP: ciprofloxacin, C: chloramphenicol, GM: gentamycin, FR: furazolidone, SXT: co-trimoxazole, LP: lincospectin, TE: tetracycline, S: Susceptible, I: Intermediate, R: Resistant. 
[20]. According to the results of this study turkeys may have an important role to dispread Salmonella in the environment. Due to high incidence of drug resistance among Salmonella spp. isolated from turkeys, it could conclude that antibiotic resistance can be resulted from unusual use of antibiotics.

\section{Recommendations}

Effort is need to control Salmonellosis in poultry flocks to reduce the threat of this organism for public health. Besides, care must be taken in the use of antibiotics to reduce drug resistant strains of Salmonella. Antibiotic resistance could be prevented with antibiogram test before drug administration or by avoiding incorrect use of antibiotics in food animals.

\section{References}

[1] Thyagarajan, D. (2011) Diseases of Poultry. 1st Edition, Satish Serial Publishing House, Delhi.

[2] Saif, Y.M., Fadly, A.M., Glisson, J.R., McDougald, L.R., Nolan, L.K. and Swayne, D.E. (2008) Diseases of Poultry. 12th Edition, Iowa State Press, Iowa.

[3] Vo, A.T., Van Duijkeren, E., Fluit, A.C., Heck, M.E., Verbruggen, A., Maas, H.M. and Gaastra, W. (2006) Distribution of Salmonella enterica Serovars from Humans, Livestock and Meat in Vietnam and the Dominance of Salmonella Typhimurium Page Type 90. Veterinary Microbiology, 113, 153-158. http://dx.doi.org/10.1016/j.vetmic.2005.10.034

[4] Carrique-Mas, J.J., Papadopoulou, C., Evans, S.J., Wales, A., Teale, C.J. and Davies, R.H. (2008) Trends in Phage Types and Antimicrobial Resistance of Salmonella enterica Serovar Enteritidis Isolated from Animals in Great Britain from 1990 to 2005. Veterinary Record, 162, 541-546. http://dx.doi.org/10.1136/vr.162.17.541

[5] Woodward, M.J. and Kirwan, S.E.S. (1996) Detection of Salmonella enteritidis in Eggs by the Polymerase Chain Reaction. Veterinary Record, 138, 411-413. http://dx.doi.org/10.1136/vr.138.17.411

[6] Glynn, M.K., Bopp, C., Dewitt, W., Dabney, P., Mokhtar, M. and Angulo, F.J. (1998) Emergence of Multidrug-Resistant Salmonella enterica Serotype Typhimurium DT104 Infections in the United States. New England Journal of Medicine, 338, 1333-1338. http://dx.doi.org/10.1056/NEJM199805073381901

[7] Quinn, P.J., Markey, B.K., Carter, M.E., Donnelly, W.J. and Leonard, F.C. (2002) Veterinary Microbiology and Microbial Disease. Blackwell Science, Oxford.

[8] Swayne, D.E., Glisson, J.R., Jackwood, M.W., Pearson, J.E. and Reed, W.M. (1998) A Laboratory Manual for the Isolation and Identification of Avian Pathogens. 4th Edition, American Association of Avian Pathologists, University of Pennsylvania, Kennett Square.

[9] Quinn, P.J., Carter, M.E., Markey, B. and Carter, G.R. (1994) Clinical Veterinary Microbiology. Wolf Publishing, London.

[10] Rahimi, E. (2012) Prevalence and Antimicrobial Resistance of Salmonella spp. Isolated from Retail Chicken, Turkey, and Ostrich By-Products in Iran. Revue de Medecine Veterinaire, 163, 271-275.

[11] Rahimi, E., Ameri, M., Kazemeini, H.R. and Elbagi, M. (2010) Prevalence and Antimicrobial Resistance of Salmonella Isolated from Retail Raw Turkey, Ostrich, and Partridge in Iran. Bulgarian Journal of Veterinary Medicine, 13, 23-30.

[12] Mayrhofer, S., Paulsen, P., Smulders, F.J. and Hilbert, F. (2004) Antimicrobial Resistance Profile of Five Major FoodBorne Pathogens Isolated from Beef, Pork and Poultry. International Journal of Food Microbiology, 97, 23-29. http://dx.doi.org/10.1016/j.ijfoodmicro.2004.04.006

[13] Jahantigh, M. and Nili, H. (2010) Drug Resistance of Salmonella spp. Isolated from Pigeon Eggs. Comparative Clinical Pathology, 19, 437-439. http://dx.doi.org/10.1007/s00580-010-1005-6

[14] Nazer, A.H.K. and Safari, G.H. (1994) Bacterial Flora from Dead-in-Shell Chicken Embryos and Their Drug Resistance in Fars Province of Iran. Indian Journal of Animal Sciences, 64, 1006-1009.

[15] Adesiyum, A., Offiah, N., Seepersadsingh, N., Rodrigo, S., Lashley, V. and Musai, L. (2007) Antimicrobial Resistance of Salmonella spp. and Escherichia coli Isolated from Table Eggs. Food Control, 18, 306-311. http://dx.doi.org/10.1016/j.foodcont.2005.10.013

[16] Graziani, C., Busani, L., Dionisi, A.M., Lucarelli, C., Owczarek, S., Ricci, A., Mancin, M., Caprioli, A. and Luzzi, I. (2008) Antimicrobial Resistance in Salmonella enterica Serovar Typhimurium from Human and Animal Sources in Italy. Veterinary Microbiology, 128, 414-418. http://dx.doi.org/10.1016/j.vetmic.2007.10.017

[17] Pan, Z., Wang, X., Zhang, X., Geng, S., Chen, X., Pan, W., Cong, Q., Liu, X., Jiao, X. and Liu, X. (2009) Changes in Antimicrobial Resistance among Salmonella enterica Subspecies Enterica Serovar Pullorum Isolates in China from 1962 to 2007. Veterinary Microbiology, 136, 387-392. http://dx.doi.org/10.1016/j.vetmic.2008.11.015

[18] Pan, Z.M., Geng, S.Z., Zhou, Y.Q., Liu, Z.Y., Fang, Q., Liu, B.B. and Jiao, X.A. (2010) Prevalence and Antimicrobial 
Resistance of Salmonella sp. Isolated from Domestic Animals in Eastern China. Journal of Animal and Veterinary Advances, 9, 2290-2294. http://dx.doi.org/10.3923/javaa.2010.2290.2294

[19] Van Duijkeren, E., Wannet, W.J.B., Houwers, D.J. and Van Pelt, W. (2003) Antimicrobial Susceptibilities of Salmonella Strains Isolated from Humans, Cattle, Pigs, and Chickens in the Netherlands from 1984 to 2001. Journal of Clinical Microbiology, 41, 3574-3578. http://dx.doi.org/10.1128/JCM.41.8.3574-3578.2003

[20] Foley, S.L. and Lynne, A.M. (2008) Food Animal-Associated Salmonella Challenges: Pathogenicity and Antimicrobial Resistance. Journal of Animal Science, 86, E173-E187. http://dx.doi.org/10.2527/jas.2007-0447 